\title{
Identification of the blue light intensity administered to one eye required to suppress bovine plasma melatonin and investigation into effects on milk production in grazing dairy cows
}

\author{
Barbara A. Murphy, ${ }^{1} \odot$ Mary M. Herlihy, ${ }^{2} \odot$ Margaret B. Nolan, ${ }^{1} \odot$ Christiane O'Brien, ${ }^{3}$ John G. Furlong, ${ }^{4} \odot$ \\ and Stephen T. Butler ${ }^{2 *}$ (1) \\ ${ }^{1}$ School of Agriculture and Food Science, University College Dublin, Belfield, Dublin 4, Ireland D04 N2E5 \\ ${ }^{2}$ Teagasc, Animal and Grassland Research and Innovation Centre, Moorepark, Fermoy, Co. Cork, Ireland P61 C996 \\ ${ }^{3}$ Equilume Ltd., W9H Ladytown Business Park, Naas, Co. Kildare, Ireland W91 RT72 \\ ${ }^{4}$ School of Veterinary Science, University College Dublin, Belfield, Dublin 4, Ireland D04 N2E5
}

\section{ABSTRACT}

Long-day photoperiod is known to positively affect milk production in confinement dairy systems, and it has been hypothesized that pineal melatonin (MT) secretion plays a substantial role in this process. Specialized mammalian photoreceptors that regulate MT secretion are optimally stimulated by short wavelength blue light. We investigated the blue light intensity administered to one eye required to suppress MT secretion in nonlactating dairy cows, and subsequently examined effects on milk production in grazing dairy cows. Following a 14-d light-dark 8:16 h environmental conditioning period, 5 nonlactating Holstein-Friesian cows were exposed to treatments of $<1,70,125,175$, and $225 \mathrm{~lx}$ for 8 additional hours using a $5 \times 5$ Latin square design. Light was administered via headpieces fitted with light-emitting diodes emitting blue light (465 nm) to the right eye. All cows were then exposed to a light-dark 16:8 $\mathrm{h}$ cycle for one night via the indoor lighting system (>200 lx white light). Plasma samples collected at regular intervals were assayed for MT. A dose-dependent effect of light treatment on mean circulating MT concentrations (and 95\% CI) was observed [9.4 (7.2, 12.3), $5.0(3.8,6.6), 4.4(3.3,5.7), 3.3(2.5$, $4.3)$ and $1.7(1.3,2.3) \mathrm{pg} / \mathrm{mL}$ for treatments of 0,70 , 125,175 , and $225 \mathrm{~lx}$, respectively. Only the $225 \mathrm{~lx}$ treatment acutely suppressed plasma melatonin concentration to levels similar to the light-dark $16: 8 \mathrm{~h}$ treatment $[1.9(1.4,2.5) \mathrm{pg} / \mathrm{mL}]$. Forty spring-calving cows were blocked on parity, calving date and Economic Breeding Index for milk production and assigned to the control treatment or blue light to a single eye (LT) treatment

\footnotetext{
Received March 26, 2021.

Accepted July 1, 2021.

*Corresponding author: stephen.butler@teagasc.ie
}

from calving through 32 wk of lactation. The cows assigned to LT treatment were fitted with headpieces providing $225 \mathrm{~lx}$ of blue light to the right eye from 1700 until $0000 \mathrm{~h}$. Mean milk production (and 95\% CI) during $32 \mathrm{wk}$ of lactation was not affected by treatment [20.3 (19.3, 21.3) vs. $20.9(19.8,22.0) \mathrm{kg} / \mathrm{d}$, control and LT, respectively]. Within multiparous cows, a treatment by week interaction was detected, whereby LT treatment increased milk production during the first 12 wk of lactation $[25.8(24.3,27.3)$ vs. $28.0(26.5,29.5)$ $\mathrm{kg} / \mathrm{d} ;+8.5 \%]$, but had no effect thereafter. Treatment did not affect plasma insulin-like growth factor 1 . We identified the blue light intensity to one eye required to acutely suppress MT concentrations. Transient favorable effects on milk production were observed in multiparous cows. It remains unclear how single-eye blue light treatment affects galactopoiesis in grazing dairy cows, and further research is needed to explore whether this modality of light delivery represents a useful means to aid productivity in pasture-based dairy systems.

Key words: melatonin, photoperiod, blue light, milk production, insulin-like growth factor 1

\section{INTRODUCTION}

Photoperiod manipulation is widely used within the agricultural food sector to increase production and efficiency, most notably in poultry (Lewis, 2006; Jácome et al., 2014) and dairy cows (Dahl and Petitclerc, 2003). The first observation that artificially extending daylight hours could positively influence milk production in lactating dairy cows was made in 1978 (Peters et al., 1978) and since then, several studies have supported these initial findings (see review by Dahl et al., 2000). All studies reiterated that providing lactating cows with light 16 to $18 \mathrm{~h} / \mathrm{d}$ can increase milk yield by approximately $2 \mathrm{~kg} / \mathrm{d}$ compared with a shorter photoperiod of 8 to $13 \mathrm{~h} / \mathrm{d}$. 
Changes in melatonin (MT) secretion from the pineal gland is a physiological response to changes in photoperiod, and represents a likely mechanism for photoperiod effects on milk production. The approximate 24-h (circadian) rhythm of MT secretion from the pineal gland is one of the most stable outputs from the circadian system (Benloucif et al., 2005). Photoperiodic information travels from the retina to the seat of the mammalian master clock in the suprachiasmatic nucleus (SCN) of the hypothalamus (Moore and Eichler, 1972; Stephan and Zucker, 1972). The molecular interplay of core clock gene products within the SCN controls the circadian output to the pineal gland (Perreau-Lenz et al., 2004) and dictates the timing of MT production and release (Bartness et al., 1993). Melatonin is synthesized and secreted solely during the dark period of the light-dark cycle; elevated plasma MT represents the duration of darkness, mirroring the seasonal changes in the length of day and night (Bartness and Goldman, 1989). Thus, this neuroendocrine pathway acts as a signal from the clock to the body conveying seasonal timing information to organs involved in reproduction and growth in both seasonal and nonseasonal breeding animals (Hansen, 1985; Morgan and Mercer, 1994).

Administration of slow-release melatonin implants to grazing dairy cows during summer (Auldist et al., 2007) was previously shown to reduce milk yield and provides evidence of a role for melatonin in the photoperiodic regulation of seasonal milk production. Although its precise mechanistic role in the regulation of lactation is not fully known, its function as a marker of photoperiod manipulation is accepted. Absolute levels of circulating MT are not just photoperiod dependent, but also reflect the physiological state of the animal (Gomes et al., 2021). It has also been suggested that it is the rate of change of light level that drives the circannual changes in milk production (Salfer et al., 2019).

Although not a strict seasonal breeder, many reproductive phenomena such as onset of puberty (Hansen et al., 1983; Kassim et al., 2008), return to cyclicity following parturition (Hansen and Hauser, 1983), and semen characteristics (Roussel et al., 1963, 1964) are influenced by photoperiod in cattle. Melatonin production is strongly circadian in the cow (Berthelot et al., 1990; Eriksson et al., 1998), and its signaling plays an important role in regulation of the somatotropic axis and the seasonal pattern of release of prolactin and IGF-1 in cows (Dahl et al., 2000). A short duration of MT secretion stimulated by a long-day photoperiod (LDPP) reportedly increases circulating prolactin and IGF-1 concentrations, and these endocrine shifts are consistent with previously observed effects on lactation, body growth, and carcass composition in cattle (Dahl et al., 2002). The specific mechanism responsible for greater circulating IGF-1 concentrations in cows exposed to longer photoperiod is unknown.

The commercial applications of extending day length to improve dairy cow production efficiency have resulted in increased interest in determining the optimum light intensity for eliciting these effects. Lawson and Kennedy (2001) investigated the threshold levels of indoor housing white light intensity required to suppress circulating MT concentrations to daytime levels in dairy heifers. Their findings suggested that less than $50 \mathrm{~lx}$ may be sufficient to prevent the initial nocturnal rise in plasma MT, but that intensities exceeding 400 $\mathrm{lx}$ may be required to sustain this suppression for $8 \mathrm{~h}$ on the first occasion of exposure (Lawson and Kennedy, 2001).

It is now known that blue, short wavelength light (465-485 nm), optimally stimulates a set of novel photoreceptors in the mammalian retina that regulate the SCN in the hypothalamus (Brainard et al., 2001; Thapan et al., 2001). These intrinsically photosensitive retinal ganglion cells (ipRGC) contain a pigment called melanopsin (Provencio et al., 2000) and work in conjunction with photopigments in rods and cones to regulate biological rhythms (Berson, 2002; Hanifin and Brainard, 2007). Recent research in humans and horses has revealed a dose-dependent suppression of the pineal hormone MT by blue light (West et al., 2011; Walsh et al., 2013). Furthermore, the provision of blue light to one eye via a specialized head piece for horses was shown to advance the onset of seasonal reproductive activity (Murphy et al., 2014) and influence gestation length, foal birth weight, and foal hair coat at birth in horses (Nolan et al., 2017).

Our first objective was to identify the threshold level of blue light administered to a single eye in the dairy cow necessary to suppress plasma MT to concentrations observed in well-lit housing. Our second objective was to determine if incorporation of the identified threshold light intensity into a specialized headpiece that provided extended lighting to cows at pasture would affect milk yield. We tested the hypothesis that delivering blue light sufficient to suppress plasma MT concentrations to mimic $18 \mathrm{~h}$ of light per day would increase milk production in grazing dairy cows.

\section{MATERIALS AND METHODS}

\section{Animals and Experimental Protocol}

All experimental procedures involving cows were approved by the Teagasc Animal Ethics Committee and authorized by the Health Products Regulatory Authority, which is the competent authority in Ireland responsible for the implementation of European Union 


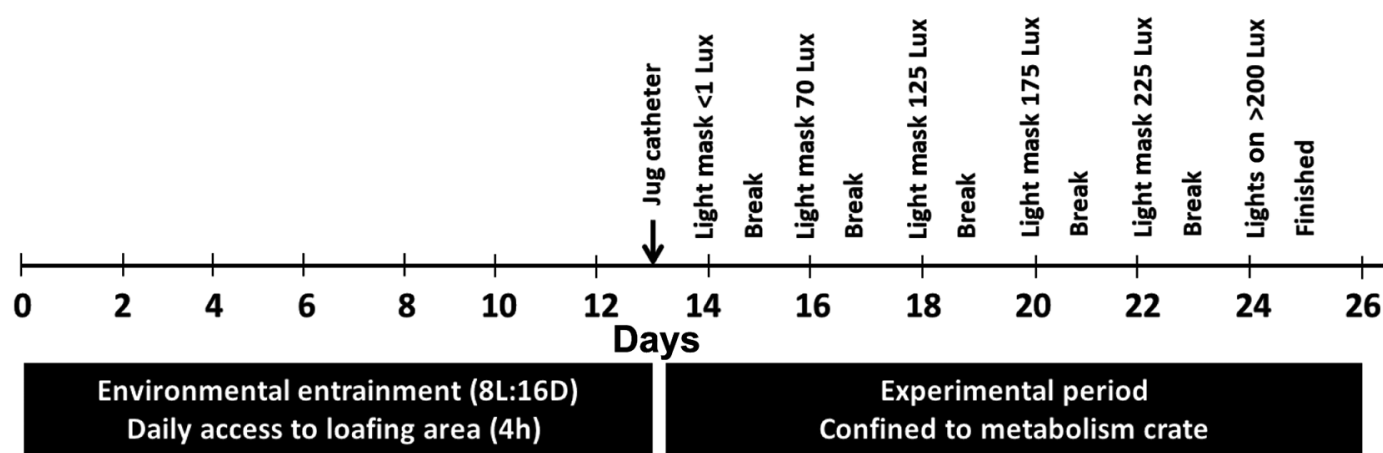

Figure 1. Schematic outline of the experimental protocol for an example sequence of blue light treatments. Cows were allowed a 2-wk period of environmental entrainment to allow adjustment to a photoperiod of $8 \mathrm{~h}$ of light, $16 \mathrm{~h}$ of dark (8L:16D). Indwelling jugular (Jug) catheters were fitted on $\mathrm{d} 13$, and cows were exposed to a random sequence of blue light treatments from 1600 to $0000 \mathrm{~h}$ on $\mathrm{d} 14,16,18,20$, and 22 . On d 24, all cows were exposed to overhead lighting from 1600 to $0000 \mathrm{~h}$.

legislation (Directive 2010/63/EU) for the protection of animals used for scientific purposes. The study was conducted at the dairy unit experimental herd of Teagasc Moorepark, Ireland $\left(52^{\circ} 8^{\prime} 9^{\prime \prime} \mathrm{N} ; 8^{\circ} 16^{\prime} 33^{\prime \prime} \mathrm{W}\right.$; altitude: $71 \mathrm{~m}$ above sea level).

Study 1. In November 2015, 5 healthy, nonlactating Holstein-Friesian cows were exposed to a 14-d environmental conditioning period that comprised $8 \mathrm{~h}$ of light, $16 \mathrm{~h}$ of dark (8L:16D), where mean $( \pm \mathrm{SD})$ white light intensity levels by day $(0800-1600 \mathrm{~h}$ ) at eye level were $237 \pm 68 \mathrm{~lx}$. This photoperiod entrainment ensured that there were no carryover effects from the longer natural day lengths the experimental animals were exposed to before the study. During this entrainment period, walking and socialization were facilitated by moving the cows from the metabolism shed, where they were housed in individual stalls, to a loose-housed straw-bedded pen with access to natural daylight for 4 $\mathrm{h}$ each day (0830-1230 h). Environmental lighting in the loafing area was also measured daily. On the d 13 of the entrainment period, indwelling jugular catheters were fitted using aseptic technique, and the animals were confined to the metabolism shed for 12 consecutive days thereafter. This ensured complete elimination of external environmental influences on MT secretion. The metabolism chamber was light-proofed such that at lights-off $(1600 \mathrm{~h})$, the ambient light level was $<1 \mathrm{~lx}$, and further husbandry procedures and sample collection were conducted using dim red light from head-mounted or hand-held flashlights. Beginning on d 14, each cow was exposed to each of 5 different light intensities $(<1,70,125,175$, and $225 \mathrm{~lx})$ for 8 additional hours (1600-0000 h) using a $5 \times 5$ Latin square design (Figure 1). Each treatment night was followed by a break night, where the animals again received 8L:16D. Two days after completion of the different light intensity treatments, all cows were exposed to the indoor lighting system until 0000 h (LT-ON). Each light treatment was administered using an adaptation of a previously developed light-emitting diode (LED) lighting system and electronic platform designed for horses (Walsh et al., 2013) that provided short wavelength blue light $(468 \mathrm{~nm})$ to the right eye and was incorporated into a custom designed headpiece to fit a dairy cow. Prototype bovine light masks were designed to fit comfortably according to the specific dimensions of the cow's head conformation. The $<1 \mathrm{~lx}$ treatment was provided by fitting a mask without a functional LED light source. For the duration of the study, cows were fed ad libitum grass silage once a day (22\% DM, $72 \%$ DM digestibility, $14.6 \% \mathrm{CP}$ ), and refusals were removed daily.

Study 2. The results of study 1 informed the light intensity for use in study 2. A power analysis was conducted to determine how many cows would be required to detect a $2 \mathrm{~kg} / \mathrm{d}$ difference in milk yield between treatments (difference to detect $=2 \mathrm{~kg}$ ). Assuming a standard deviation of $2 \mathrm{~kg} / \mathrm{d}$ for milk yield, significance level $(\alpha)=0.05$, and power $(1-\beta)=0.8$, the minimum number of animals required per treatment was 16 cows. Forty spring-calving Holstein-Friesian cows were blocked based on parity, calving date, and Economic Breeding Index for milk production and randomly assigned to either a control treatment (CTL) or blue light to a single eye (LT) treatment from day of calving through 32 wk of lactation (February to October 2017). The median calving date of the cows enrolled in the study was February 15 (range: January 25 to March 31 ). On the day of calving, the LT cows were fitted with light masks providing $225 \mathrm{~lx}$ of blue light to the right eye that activated on a timer from 1700 until $0000 \mathrm{~h}$ daily (16L:8D to $18 \mathrm{~L}: 6 \mathrm{D}$, as season progressed). The CTL cows were exposed to the natural photoperiod changes and daylight intensities at the study location (Figure 2). Cows were milked twice daily at 0730 and $1500 \mathrm{~h}$, 


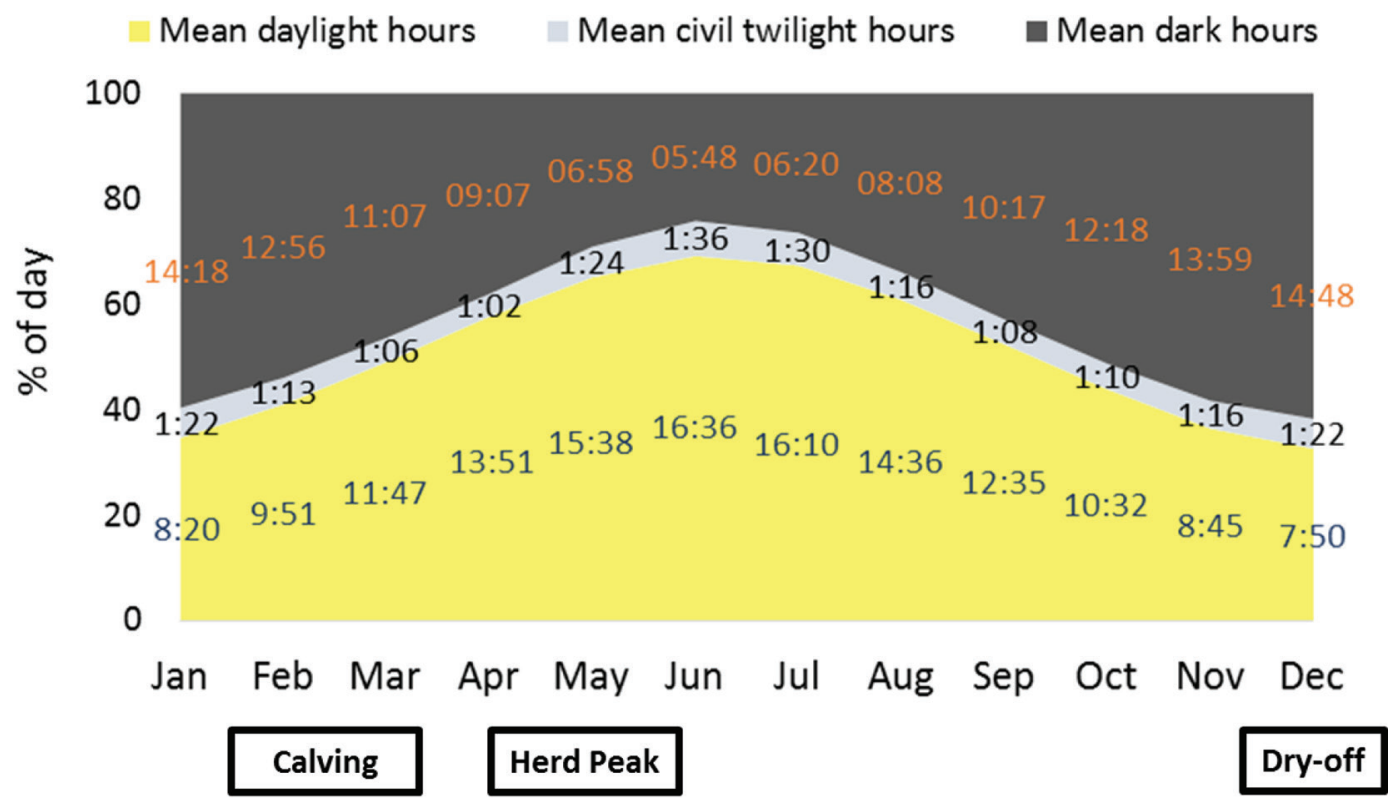

Figure 2. Seasonal changes in the natural photoperiod at Moorepark Animal and Grassland Research and Innovation Centre $\left(52^{\circ} 8^{\prime} 9^{\prime \prime} \mathrm{N}\right.$; $8^{\circ} 16^{\prime} 33^{\prime \prime} \mathrm{W}$; altitude: $71 \mathrm{~m}$ ). Civil twilight is defined as the time it takes for the sun to move from (at sunrise) or to (at sunset) $6^{\circ}$ below the horizon and when there is enough light to carry out everyday activities. Cows calve in late winter or early spring when there are between 9 to $12 \mathrm{~h} / \mathrm{d}$ of daylight. Peak milk production coincides with long-day photoperiod. The dry period coincides with the shortest day photoperiod.

and milk yield $(\mathrm{kg})$ was recorded at both the morning and evening milking using electronic milk meters (Dairy Master) and collapsed to provide weekly mean milk production throughout lactation. Milk composition (fat, protein, and lactose) was determined on $2 \mathrm{~d} /$ wk from successive evening and morning milk samples using a Milkoscan 605 (Foss Electric). The cows were stocked at 2.75 cows/ha, and allocated a daily pasture allowance of approximately $18 \mathrm{~kg}$ of DM/cow to achieve a postgrazing sward height of $4 \mathrm{~cm}$. Rotational grazing was implemented from February to November. Target pregrazing herbage mass was 1,400 to $1,600 \mathrm{~kg}$ of DM/ ha. The swards were a mixture of perennial ryegrass (Lolium perenne L.) and perennial ryegrass plus clover (Trifolium repens L.).

Body weight was recorded weekly, and BCS was recorded every 2 wk using a 1 to 5 scale in increments of 0.25 (Edmonson et al., 1989). Light masks were checked for positioning, and the lens of the light source cleaned once every 2 wk. Light masks were replaced when the light source was damaged or had become detached from the headpiece.

\section{Blood Sampling}

Blood samples were collected from indwelling jugular catheters (study 1) or from the coccygeal vessels (study 2) into evacuated lithium heparin tubes (Vacutainer,
Becton Dickinson). Samples were centrifuged for 15 min at $1,500 \times g$ and $4^{\circ} \mathrm{C}$, and plasma was harvested and stored at $-20^{\circ} \mathrm{C}$ until further analysis.

Study 1. A blood sample was collected from each animal at $1600 \mathrm{~h}$ immediately before overhead lights were turned off and light mask treatments were turned on, and additional samples were collected at 1700 , 1800, 2000, 2300, and $0000 \mathrm{~h}$, which encompassed the 8-h period of light mask treatments. All light masks were turned off at $0000 \mathrm{~h}$, and a final blood sample was collected one hour later at $0100 \mathrm{~h}$. All blood samples were used for determination of plasma MT concentrations. A previous study evaluating circulating melatonin concentrations in dairy cows at $30 \mathrm{~min}$ intervals over $24 \mathrm{~h}$ under multiple photoperiod regimens clearly demonstrated that regardless of photoperiod $(8 \mathrm{~L}: 16 \mathrm{D}$ or $16 \mathrm{~L}: 8 \mathrm{D}$ ), serum melatonin concentrations decline from increased night-time concentrations to basal concentrations during daytime hours, precluding the need to sample throughout the night (Lacasse et al., 2014). On break nights, blood samples were collected at 1800 and $2200 \mathrm{~h}$ for determination of plasma MT levels. The samples were collected on break nights to verify that there were no carryover effects of the previous night's treatment on plasma MT concentrations.

Study 2. Blood samples were collected from each animal within $48 \mathrm{~h}$ after calving, and on wk 2, 4, 6, $8,12,16,20,24,28$, and 32 after calving at $0800 \mathrm{~h}$ 
following morning milking for determination of plasma IGF-1.

\section{Radioimmunoassay}

Melatonin was measured in all samples collected in study 1 using a Bühlmann melatonin RIA kit (RKMEL2, ALP-CO Diagnostics). Plasma aliquots (500 $\mu \mathrm{L})$ were column-extracted using a vacuum manifold (Visiprep-DL Solid Phase Extraction Vacuum Manifold; Supelco) according to the directions of the manufacturer and reconstituted in $500 \mu \mathrm{L}$ of incubation buffer solution provided with the kit. Aliquots of the reconstituted extracted samples $(200 \mu \mathrm{L})$ were assayed in duplicate. The inter- and intra-assay coefficients of variation for low and high MT controls were 10.8 and $12.9 \%$; and 6.2 and $4.7 \%$, respectively. As documented by the manufacturer, the efficiency of the extraction method was $>90 \%$, and the assay had an estimated functional sensitivity of $0.9 \mathrm{pg} / \mathrm{mL}$ (coefficient of variance, $10 \%)$ and an estimated analytical sensitivity of $0.3 \mathrm{pg} / \mathrm{mL}$. This assay has been used previously to examine MT concentrations in bovine plasma (Lawson and Kennedy, 2001). Plasma IGF-1 was measured following ethanol-acetone-acetic acid (6:3:1) extraction using a radioimmunoassay as previously described by Beltman et al. (2010). The sensitivity of the assay was $6 \mathrm{pg}$ per tube $(6 \mathrm{ng} / \mathrm{mL})$. The inter- and intra-assay coefficients of variance for low, medium, and high serum IGF-1 controls were 3.3 and $16.4 \%, 1.7$ and $10.9 \%$, and 1.3 and $5.5 \%$, respectively. Mean serum IGF-1 concentrations for low, medium, and high controls were 58.9, 156.87 , and $280.6 \mathrm{ng} / \mathrm{mL}$, respectively.

\section{Statistical Analyses}

Study 1. Plasma MT concentration data were log-transformed and analyzed using SAS (SAS Institute Inc.). For the 5 nights of different light intensity treatments delivered to a single eye, plasma MT data were analyzed using a mixed model with treatment, period, hour, and treatment $\times$ hour included as fixed effects, and cow was included as a random effect. For the single night when all cows were exposed to the LTON treatment, plasma MT data were analyzed using a mixed model with hour as a fixed effect, and cow was included as a random effect. Plasma MT data from the 4 break nights were analyzed using a mixed model with hour and treatment $\times$ hour included as fixed effects, and cow was included as a random effect. The TukeyKramer adjustment was used to correct for multiple comparisons. Plasma MT data are presented as back transformed means with $95 \%$ confidence intervals. $P$ values $<0.05$ were considered significant.
Study 2. Mean daily milk yield (kg/d), BCS, BW, and plasma IGF-1 concentrations were analyzed using SAS (SAS Institute Inc.) mixed models with treatment, week of lactation, parity and all 2-way interactions with treatment as fixed effects, and cow as a random effect. $P$-values $<0.05$ were considered significant. Data are presented as means \pm SEM.

\section{RESULTS}

\section{Study 1}

A dose-dependent effect of blue light treatment on mean circulating MT concentrations between 1600 and $0000 \mathrm{~h}$ was observed $(P<0.0001$; Figure $3 \mathrm{~A})$. Mean baseline plasma MT concentration did not differ $(P>$ 0.05 ) between treatments at $1600 \mathrm{~h}$ when the cows were still exposed to the final minutes of the basic 8-h photoperiod $(237 \pm 68 \mathrm{~lx})$, or at $1 \mathrm{~h}$ after the light treatments commenced (1700 h; all $P>0.05)$. At $1800 \mathrm{~h}$, the $<1 \mathrm{~lx}$ treatment had greater plasma MT compared with the treatments of 125, 175, and $225 \mathrm{~lx}$ (all $P<0.01$ ). At 2000,2300 , and $0000 \mathrm{~h}$, there were no differences (all $P$ $>0.05$ ) between $<1 \mathrm{~lx}$ and either the 70 or $125 \mathrm{~lx}$ treatments, but 175 and $225 \mathrm{~lx}$ treatments had lesser (all $P$ $<0.001$ ) plasma MT compared with $<1 \mathrm{~lx}$. There were no differences in plasma MT concentration between 175 and $225 \mathrm{~lx}$ at any individual time point (all $P>0.05$ ). The $225 \mathrm{~lx}$ treatment had lesser plasma MT compared with $70 \mathrm{~lx}(1800,2000,2300$, and $0000 \mathrm{~h}$; all $P<0.02)$ and $125 \mathrm{~lx}(2000,2300$, and $0000 \mathrm{~h}$; all $P<0.02)$, but $175 \mathrm{~lx}$ did not differ from 70 or $125 \mathrm{~lx}$ at any time point (all $P>0.05$ ). After the light treatments ceased and all cows had been exposed to dark for $1 \mathrm{~h}(0100 \mathrm{~h})$, there were no differences in plasma MT between any of the treatments (all $P>0.9$; Figure 3B).

The LT-ON treatment was not included in the statistical analysis of the Latin square design light treatment administered via a head mask, but the plasma MT concentrations are included in Figure 3 for comparison. Based on overall mean plasma MT (Figure 3A) and the temporal profile of plasma MT (Figure 3B), only the 225 lx treatment recapitulated the effects of the LT-ON treatment on plasma MT concentrations.

On break nights, there was an effect of time $(P<$ $0.0001)$ but no effect of night $(P=0.45)$ on plasma MT concentrations (Figure 3C). At 1800 h, mean (95\% CI) plasma MT concentrations were consistently low [4.93 $(3.44,6.42) \mathrm{pg} / \mathrm{mL}]$ and at $2200 \mathrm{~h}$, plasma MT concentrations were consistently elevated [20.65 (19.16, 22.14) $\mathrm{pg} / \mathrm{mL}$. These data confirm that there were no carryover effects of the previous night's treatment on subsequent plasma MT concentrations the following night. 
A
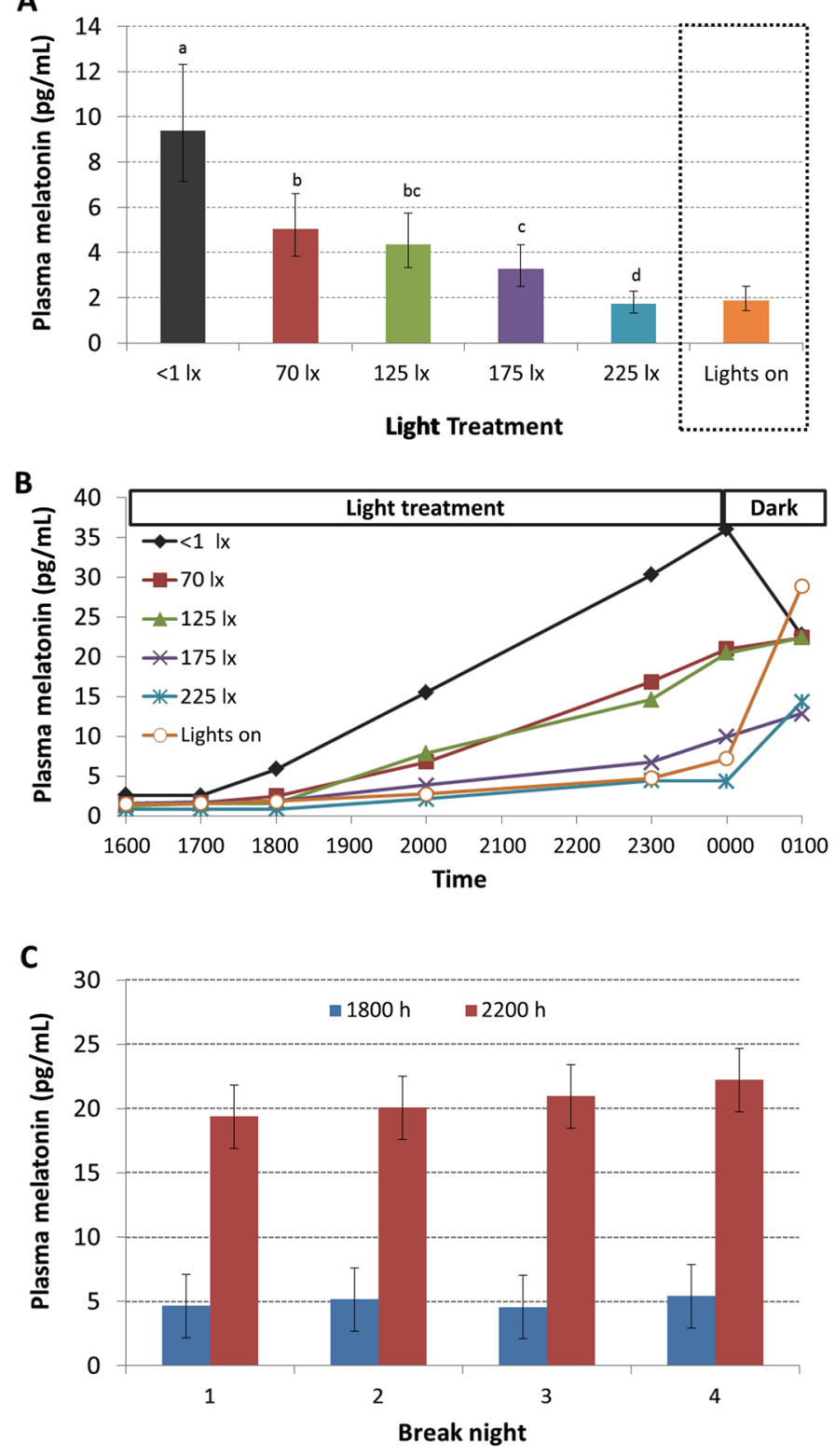

Figure 3. Plasma melatonin response to light treatment. (A) Mean plasma melatonin concentrations during the 8-h period of light treatment (1600 to $0000 \mathrm{~h})$. Lights on was not included as a treatment, and data are included for comparison only. A treatment effect $(P<0.001)$ was observed for the light mask treatments. The error bars indicate the $95 \%$ confidence interval. Treatments with different letters (a, b, c) indicate significant differences $(P<0.05)$. (B) Temporal profile of plasma melatonin concentrations during the 8 -h period of light treatment (16:00 to 00:00) and $1 \mathrm{~h}$ after light treatments ceased. Lights on was not included as a treatment, and data is included for comparison only. A treatment $\times$ time interaction $(P=0.004)$ was observed for the light mask treatments. (C) Plasma melatonin concentrations on each of the 4 break nights at 1800 and $2200 \mathrm{~h}$. The effect of hour was significant $(P<0.001)$, but there was no effect of night $(P=0.45)$. The error bars indicate the $95 \%$ CI.

\section{Study 2}

Of the 40 cows enrolled in the study, 2 CTL cows and $1 \mathrm{LT}$ cow were removed from the study due to ill health unrelated to the experiment or due to incorrect expected calving date. Hence, 18 CTL cows (6 primiparous and 12 multiparous) and 19 LT cows (6 primiparous and 13 multiparous) completed the study. Mean (95\% CI) milk production during 32 wk of lactation was not affected by treatment $[20.3(19.3,21.3)$ vs. 20.9 $(19.8,22.0) \mathrm{kg} / \mathrm{d}, P=0.4$; CTL and $\mathrm{LT}$, respectively, Figure $4 \mathrm{~A}]$. Within multiparous cows, a treatment $\times$ week interaction was detected $(P=0.048)$, whereby LT treatment increased milk production during the first 12 wk of lactation $[25.8(24.3,27.3)$ vs. $28.0(26.5,29.5)$ $\mathrm{kg} / \mathrm{d} ;+8.5 \%$ ], but had no effect thereafter (Figure 4B). There were no effects of treatment, or interactions between treatment and week of lactation or treatment and parity on milk solids yield ( $\mathrm{kg}$ of protein plus fat), milk composition (fat, protein, and lactose \%), BW, or BCS (Table 1). There were no effects of treatment $(P=$ $0.19)$ or interactions between treatment and parity $(P$ $=0.56)$ or treatment and week of lactation $(P=0.44)$ on plasma IGF-1 (Figure 5).

\section{DISCUSSION}

Numerous previous studies have confirmed the galactopoietic effects of LDPP in lactating dairy cows. In all cases, stimulatory photoperiods were provided via timed illumination from fixed light sources in indoor housing environments. In the present studies, we identified the threshold level of blue light delivered to a single eye via a head worn mask required to suppress plasma MT concentrations in dairy cows, and evaluated the effects of this level of blue light on milk production in grazing dairy cows. Previous investigations of indoor confinement lighting systems that elicited milk production responses to LDPP in cows include use of fluorescent, metal halide and high-pressure sodium lights (Peters et al., 1978; Lawson and Kennedy, 2001; Kennedy et al., 2004; Rius and Dahl, 2006), with light intensities ranging from 50 to $400+\mathrm{lx}$ measured at eye level. These regimens for photoperiod management require indoor housing of animals, which is associated with greater costs related to feeding, management, and energy utilization (Lawson and Kennedy, 2001; Fariña et al., 2011). However, the productivity gains may outweigh the costs associated with these management regimens. The primary physiological marker of LDPP lighting regimens is suppression of pineal melatonin production and secretion (Stanisiewski et al., 1988; Muthuramalingam et al., 2006; Kassim et al., 2008) 
Table 1. Treatment (Trt) ${ }^{1}$ effects on mean (95\% CI) milk solids yield, milk composition, BW, and BCS during 32 wk of lactation

\begin{tabular}{|c|c|c|c|c|c|}
\hline Item & Control & Light & \multicolumn{3}{|c|}{$P$-value } \\
\hline Milk solids $(\mathrm{kg} / \mathrm{d})$ & $1.40(1.18,1.66)$ & $1.55(1.30,1.83)$ & 0.40 & 0.99 & 0.68 \\
\hline Milk fat (\%) & $4.53(4.30,4.77)$ & $4.53(4.29,4.78)$ & 0.99 & 0.19 & 0.85 \\
\hline Milk lactose (\%) & $4.83(4.79,4.87)$ & $4.83(4.79,4.88)$ & 0.94 & 0.88 & 0.34 \\
\hline BW (kg) & $498(477,519)$ & $501(479,523)$ & 0.80 & 0.43 & 0.57 \\
\hline
\end{tabular}

${ }^{1}$ Control = no blue light treatment; cows exposed to the natural photoperiod changes and daylight intensities; Light $=$ exposure to blue light at $225 \mathrm{~lx}$ to the right eye from 1700 until $0000 \mathrm{~h}$ daily (16L:8D to $18 \mathrm{~L}: 6 \mathrm{D}$, as the season progressed) from day of calving to $32 \mathrm{wk}$ of lactation.

and support for the role of melatonin as regulator of lactation and prolactin secretion has been reviewed $(\mathrm{Li}$ et al., 2020). In study 1, we identified a dose-dependent effect of blue light administered to a single eye on suppression of plasma MT concentrations, and observed that intensity of $225 \mathrm{~lx}$ was required to effectively sup-

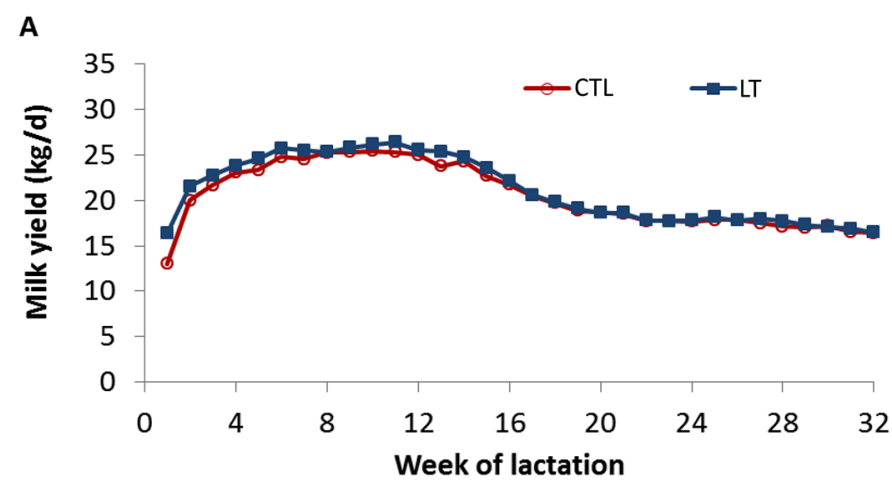

B

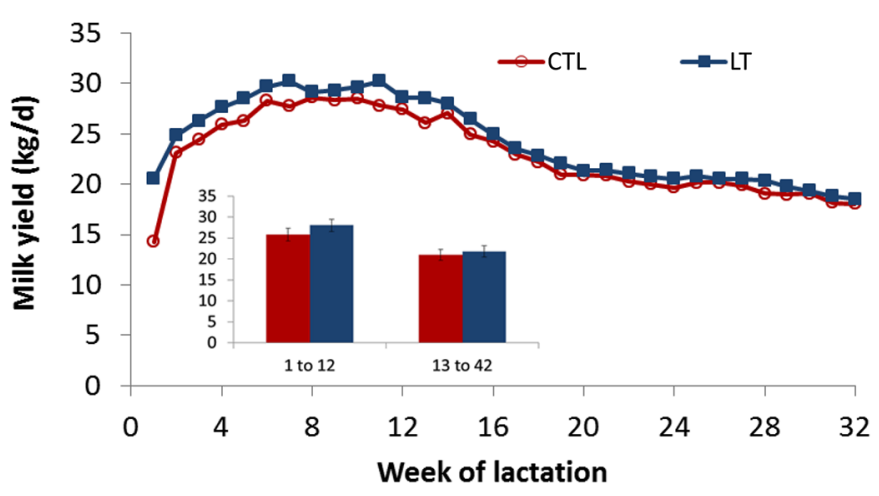

Figure 4. (A) Weekly milk production (and 95\% CI) across all cows [primiparous: control group (CTL), $\mathrm{n}=6$, and treatment group (blue light to a single eye; LT), $\mathrm{n}=6$; multiparous: $\mathrm{CTL}, \mathrm{n}=12$, and LT, $\mathrm{n}=13]$ enrolled in the study during $32 \mathrm{wk}$ of lactation. Mean was not affected by treatment $[20.3(19.3,21.3)$ vs. $20.9(19.8,22.0) \mathrm{kg} / \mathrm{d}$, CTL and LT, respectively; $P=0.4$. (B) Within multiparous cows, a treatment by week interaction was detected $(P=0.048)$, whereby LT increased milk production during the first $12 \mathrm{wk}$ of lactation. The inset depicts the mean milk production in multiparous cows during wk 1 to 12 and wk 13 to 32 , and the error bars represent $95 \%$ CI. press plasma MT concentrations to those observed in well-lit housing.

In a previous study examining suppression of circulating MT concentrations by white light, Lawson and Kennedy (2001) reported that 400 lx light intensity was required to suppress circulating MT concentrations to daytime basal concentrations. In the current study, we observed equal suppression of plasma melatonin concentrations with $225 \mathrm{~lx}$ short-wavelength blue light. Of note, this was achieved by administering the blue light to a single eye versus exposure of both eyes to ambient light in the previous work (Lawson and Kennedy, 2001). This difference in efficacy is likely explained by the wavelengths of light used. Melanopsin, the photopigment identified in ipRGC (Provencio et al., 2000), is primarily responsible for signaling photic information to the SCN and thus, regulating melatonin secretion. Melanopsin exhibits peak spectral sensitivity for shortwavelength blue light (Brainard et al., 2001; Thapan et al., 2001) that is in the range employed in the headpiece used in the current studies. Furthermore, it was recently discovered that light stimulation of a single melanopsin containing ipRGC within the retina can bilaterally innervate the SCN (Fernandez et al., 2016). Collectively, these findings may explain why blue light administration to a single eye has equal or stronger suppressive effect on melatonin secretion than ambient white light to both eyes.

In the current study, plasma MT was suppressed in response to a single exposure of $225 \mathrm{~lx}$ blue light stimulus. The term "Zeitgeber" refers to exogenous (external) cues that influence the timing of internal clocks to entrain an organism to a 24-h cycle. By definition, an endogenously generated circadian rhythm can only adapt gradually to changes in the Zeitgeber, primarily the light-dark cycle (Aschoff et al., 1975), as the system evolved to only deal with gradual seasonal changes in day length provided by the natural environment. Time is required to allow complete readjustment of molecular and cellular events that occur both in the SCN and peripheral tissues during resetting to a new $24-\mathrm{h}$ cycle 
A

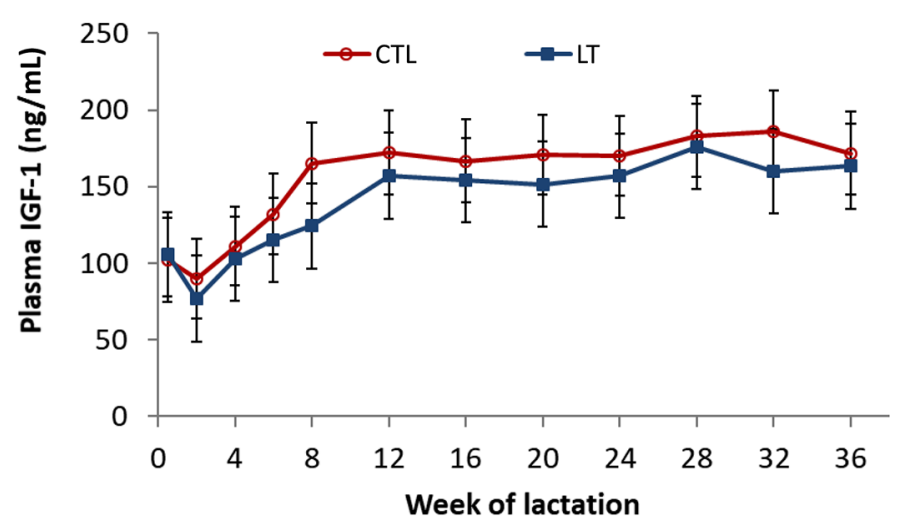

B

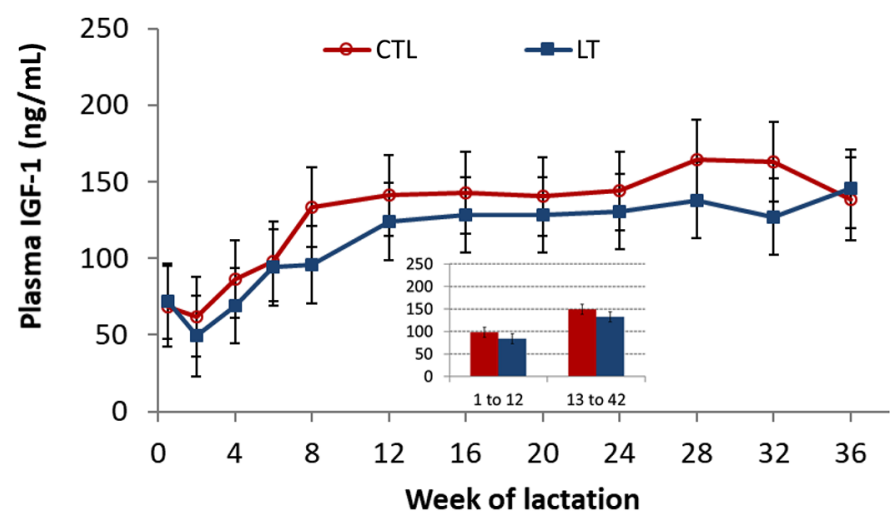

Figure 5. (A) Plasma IGF-1 concentrations from parturition to wk 36 of lactation across all cows enrolled in the study. There was no effect of treatment $(P=0.19)$ or treatment $\times$ week interaction $(P=$ 0.44). $\mathrm{CTL}=$ control treatment; $\mathrm{LT}=$ light treatment that received blue light to a single eye. (B) Within multiparous cows, there was also no effect of treatment $(P=0.29)$ or treatment $\times$ week interaction $(P$ $=0.24$ ). The inset depicts the mean plasma IGF-1 concentrations in multiparous cows during wk 1 to 12 and wk 13 to 32 . The error bars represent $95 \%$ CI.

provided by artificial light (Yamazaki et al., 2000; Reddy et al., 2002). Melatonin production from the pineal gland is considered one of the most stable outputs from the mammalian circadian clock (Benloucif et al., 2005), and multiple studies have demonstrated the gradual adaptation of melatonin rhythms following phase-shifts of the light-dark cycle (Fève-Montange et al., 1981; Kennaway, 1994; Drijfhout et al., 1997; Barnes et al., 1998). Therefore, it is speculated that the time required for complete resynchronization to an LDPP in cattle would take several days or even weeks, especially as melatonin secretion is known to be strongly circadian (Berthelot et al., 1990).

For these reasons, we hypothesize that MT suppression to daytime levels would be attained following repeated exposure to lower light intensities delivered to one eye and within the blue light spectrum. A similar hypothesis was proposed in relation to intensities of white light exposure (Lawson and Kennedy, 2001) and is supported by studies showing that repeated daily photoperiod extension using white light intensities between 114 and $231 \mathrm{~lx}$ improved cattle productivity (Peters et al., 1978, 1981). Moreover, Reksen et al. (1999) observed that repeated daily photoperiod extension with dim illumination (mean $36 \mathrm{~lx}$ ) increased milk production. Importantly, the authors noted that this response to dim light occurred when preceded by high intensity light during the day (Reksen et al., 1999). It is therefore reasonable to suggest that repeated exposure to photoperiod extension by lower blue light intensities in grazing dairy cattle exposed to bright natural daylight might facilitate the required MT suppression to elicit desired physiological responses. Future studies should evaluate MT suppression following continued nightly exposure to lower intensities of blue light to a single eye.

An additional important finding from study 1 was the lack of any observed carryover effects of the previous night's light treatment on MT patterns during break nights. On each break night, plasma MT concentrations were consistently low at $1800 \mathrm{~h}$ and high at $2200 \mathrm{~h}$ and mimicked the plasma MT pattern observed for the $<1$ $\mathrm{lx}$ treatment. An alternative finding might have confounded results. Lesser plasma MT concentrations at $2200 \mathrm{~h}$ on break nights might have suggested that the preceding treatment light intensities were serving to entrain the hormone's production pattern. The consistent results on break nights serve to further underline how regulation of melatonin requires repeated exposure to a light stimulus to elicit a gradual adaptation to a new environmental signal related to changing day length.

In study 2, we evaluated the effect of providing LDPP to individual grazing dairy cows via a wearable headpiece delivering $225 \mathrm{~lx}$ of blue light to the right eye, which negated the requirement for indoor management or lighting infrastructure. There was no milk production response in primiparous cows at any stage during the study. In contrast, multiparous cows exhibited a modest increase in milk production $(+8.5 \%)$ during the first $12 \mathrm{wk}$ of lactation, corresponding to the period from late winter to late spring. It is perhaps not surprising that light treatment did not elicit a milk production response when all cows were exposed to a natural LDPP (summer months), but interestingly light treatment also did not stimulate a milk production response in late summer and autumn months when natural photoperiodic day length was again becoming shorter.

To our knowledge this is the first controlled trial to evaluate LDPP in grazing cows for 32 wk of lactation. 
Most previous studies that examined the effect of manipulating photoperiod on milk yield in dairy cows were shorter duration, ranging from 8 to 20 wk (Peters et al., 1978, 1981; Marcek and Swanson, 1984; Bilodeau et al., 1989; Phillips and Schofield, 1989). The short study duration in these previous studies was likely a consequence of the significant practical challenges associated with maintaining a control treatment group of animals under short day conditions as the natural photoperiodic day length increases. One important study that succeeded in overcoming this was conducted by Evans and Hacker (1989), whereby the effect of various skeleton photoperiods on milk yield were evaluated in cows housed in light-proof rooms for $28 \mathrm{wk}$. The authors concluded that exposure to a light stimulus 13 to $15 \mathrm{~h}$ after subjective dawn was necessary to elicit a photoperiodic response in milk production in the dairy cow (Evans and Hacker, 1989). This is in agreement with the original hypothesis by Bunning (1960) that the photoperiodic effect of a light-dark cycle depends on the position of light relative to the photosensitive phase of an animal's endogenous circadian rhythm (Elliott, 1976).

This finding has relevance for interpreting the results of study 2, whereby control animals were naturally exposed to day lengths in excess of $13 \mathrm{~h}$ from early April, increasing to $15.5 \mathrm{~h}$ in May, and peaking at 16.5 $\mathrm{h}$ in June, without accounting for the additive effect of twilight intensities. This suggests that cows in the CTL group were exposed to light within their circadian photosensitive phase from as early as wk 4 of lactation (for cows that calved in March), and may explain the absence of treatment differences in milk production after wk 12 of lactation in spring calving cows.

A previous study that reported greater lactation persistency was initiated earlier during the winter months (Peters et al., 1981). Additional studies were conducted at lower latitudes (Marcek and Swanson, 1984; Bilodeau et al., 1989) where spring and summer day lengths are shorter than at the present study location on the 52nd parallel North. Still, this fails to explain why differences between treatments in milk production did not reemerge in the later weeks of lactation during autumn, when the LT treatment cows once again were exposed to an artificial LDPP, whereas CTL cows were exposed to a continuously shortening natural photoperiodic day length. It is feasible that the varying day lengths experienced by CTL treatment cows at specific weeks of lactation and their effect on circadian photosensitivity may have diluted the effect. Alternatively, once milk production became equal in the 2 treatments during the natural LDPP, it is possible that the LT stimulus was inadequate to stimulate an increase in milk production in cows that were in the declining phase of the lactation curve. It was also previously suggested that even though cows have been shown to respond to long days at any stage of lactation, the potential to become refractory to an extended LDPP remains unknown (Dahl and Petitclerc, 2003). Thus, refractoriness to the LDPP provided by the head mask cannot be ruled out. Another important consideration is the method by which the headpiece used in this study extended photoperiod for the treatment cows. The blue light activated each day at $1700 \mathrm{~h}$. After the summer solstice, however, the gradually advancing sunrise times that all cows were exposed to meant daily total light exposure reduced from 18.5 to $16 \mathrm{~h}$ for the treatment cows. It was previously reported that it is the direction of photoperiod change, rather than the total day length that influences reproductive physiology in seasonal breeding sheep (Robinson and Karsch, 1987). Future studies should be conducted at lower latitudes, where the maximum natural day lengths are shorter than at the current study location, and use a modified headpiece that maintains a stimulatory day length that accounts for changes in sunrise time to evaluate the effects of LDPP on milk production and lactation curve persistency during autumn in grazing cows.

Despite study limitations, the mean milk production gains observed in multiparous cows during wk 1 to 12 of lactation $(2.2 \mathrm{~kg} / \mathrm{d})$ agree with the mean production gains reported across 10 previous studies evaluating LDPP facilitated by timed exposure to white lighting from light fixtures in indoor housing (Dahl et al., 2000). Our finding that LDPP provided by a head mask did not influence milk production in primiparous cows is also consistent with previous reports (Marcek and Swanson, 1984; Vanbaale et al., 2005). Authors of previous studies did not speculate as to why primiparous cows do not respond similarly to multiparous cows to extended photoperiod. Milk yields in primiparous cows are less than in mature cows (Ray et al., 1992). As endogenous hormone production is thought to facilitate photoperiod influences on milk production, it is possible that one or more hormones associated with nutrient partitioning, lactogenesis, and galactopoiesis may be preferentially directed toward growth rather than lactation in primiparous cows. Hence, it is possible that age and stage of mammary gland development are important factors that impinge the milk production response to photoperiod.

Dahl et al. (1997) reported that cows exposed to a long photoperiod for $8 \mathrm{wk}$ had greater circulating concentrations of IGF-1 compared with cows exposed to ambient natural photoperiod. A later study from the same research group showed no effect of photoperiod on IGF-1 despite an effect on milk yield (Miller et al., 1999). In study 2 , we failed to observe an increase in 
IGF-1 in response to LT treatment throughout the 32 wk study period. Hence, our results agree with Miller et al. (1999), who concluded that IGF-1 may not be responsible for LDPP induced increases in milk production.

\section{CONCLUSIONS}

We identified that $225 \mathrm{~lx}$ was the minimum threshold intensity of blue light administered to a single eye required to acutely suppress plasma MT concentrations to basal daytime concentrations. Extension of photoperiod using blue light to one eye via head masks to lactating multiparous dairy cows caused a modest (12 week) increase in milk production compared with cows exposed to ambient natural photoperiod at the 52nd parallel. Milk production gains were similar to previous studies of LDPP provided by light fixtures in indoor housing. The precise mechanisms through which MT suppression influences galactopoiesis remain to be fully elucidated. Future studies should explore the factors that regulate milk production responses of grazing dairy cows exposed to LDPP delivered via blue light head masks.

\section{ACKNOWLEDGMENTS}

Funding from Equilume Ltd. (Naas, Co. Kildare, Ireland) and Teagasc (Fermoy, Co. Cork, Ireland) are gratefully acknowledged. We acknowledge Patrick Nolan for technical assistance during study 1 and are grateful to the farm staff at Teagasc Moorepark for the care of the animals. B.A.M. is the Founder of Equilume Ltd., a spin-out company derived from her research program as assistant professor at UCD, and is a company shareholder and member of the company's board of directors. C.O.B. was an employee of Equilume Ltd. at the time that the presented studies were conducted. The headpiece used in the presented studies has the following patents: GB2562340, GB2004819.5, HK40000337.

\section{REFERENCES}

Aschoff, J., K. Hoffmann, H. Pohl, and R. Wever. 1975. Re-entrainment of circadian rhythms after phase-shifts of the Zeitgeber. Chronobiologia 2:23-78.

Auldist, M. J., S.-A. Turner, C. D. McMahon, and C. G. Prosser. 2007. Effects of melatonin on the yield and composition of milk from grazing dairy cows in New Zealand. J. Dairy Res. 74:52-57. https: //doi.org/10.1017/S0022029906002160.

Barnes, R. G., S. J. Deacon, M. J. Forbes, and J. Arendt. 1998. Adaptation of the 6-sulphatoxymelatonin rhythm in shiftworkers on offshore oil installations during a 2 -week 12 -h night shift. Neurosci. Lett. 241:9-12. https://doi.org/10.1016/S0304-3940(97)00965-8.

Bartness, T. J., and B. D. Goldman. 1989. Mammalian pineal melatonin: A clock for all seasons. Experientia 45:939-945. https://doi .org/10.1007/BF01953051.
Bartness, T. J., J. B. Powers, M. H. Hastings, E. L. Bittman, and B. D. Goldman. 1993. The timed infusion paradigm for melatonin delivery: What has it taught us about the melatonin signal, its reception, and the photoperiodic control of seasonal responses? J. Pineal Res. 15:161-190. https://doi.org/10.1111/j.1600-079X.1993 .tb00903.x.

Beltman, M. E., N. Forde, P. Furney, F. Carter, J. F. Roche, P. Lonergan, and M. A. Crowe. 2010. Characterisation of endometrial gene expression and metabolic parameters in beef heifers yielding viable or non-viable embryos on Day 7 after insemination. Reprod. Fertil. Dev. 22:987-999. https://doi.org/10.1071/RD09302.

Benloucif, S., M. J. Guico, K. J. Reid, L. F. Wolfe, M. L'HermiteBalériaux, and P. C. Zee. 2005. Stability of melatonin and temperature as circadian phase markers and their relation to sleep times in humans. J. Biol. Rhythms 20:178-188. https://doi.org/10 $.1177 / 0748730404273983$.

Berson, D. M. 2002. Phototransduction by retinal ganglion cells that set the circadian clock. Science 295:1070-1073. https://doi.org/10 $.1126 /$ science.1067262.

Berthelot, X., M. Laurentie, J. P. Ravault, J. Ferney, and P. L. Toutain. 1990. Circadian profile and production rate of melatonin in the cow. Domest. Anim. Endocrinol. 7:315-322. https://doi.org/ 10.1016/0739-7240(90)90037-Z.

Bilodeau, P. P., D. Petitclerc, N. St. Pierre, G. Pelletier, and G. J. St. Laurent. 1989. Effects of photoperiod and pair-feeding on lactation of cows fed corn or barley grain in total mixed rations. J. Dairy Sci. 72:2999-3005. https://doi.org/10.3168/jds.S0022 $-0302(89) 79452-2$.

Brainard, G. C., J. P. Hanifin, J. M. Greeson, B. Byrne, G. Glickman, E. Gerner, and M. D. Rollag. 2001. Action spectrum for melatonin regulation in humans: evidence for a novel circadian photoreceptor. J. Neurosci. 21:6405-6412. https://doi.org/10.1523/ JNEUROSCI.21-16-06405.2001.

Bunning, E. 1960. Circadian rhythms and time measurement in photoperiodism. Cold Spring Harb. Symp. Quant. Biol. 25:249-256. https://doi.org/10.1101/SQB.1960.025.01.026.

Dahl, G. E., T. L. Auchtung, and P. E. Kendall. 2002. Photoperiodic effects on endocrine and immune function in cattle. Reprod. Suppl. 59:191-201.

Dahl, G. E., B. A. Buchanan, and H. A. Tucker. 2000. Photoperiodic effects on dairy cattle: A review. J. Dairy Sci. 83:885-893. https:/ /doi.org/10.3168/jds.S0022-0302(00)74952-6.

Dahl, G. E., T. H. Elsasser, A. V. Capuco, R. A. Erdman, and R. R. Peters. 1997. Effects of a long daily photoperiod on milk yield and circulating concentrations of insulin-like growth factor-1. J. Dairy Sci. 80:2784-2789. https://doi.org/10.3168/jds.S0022 -0302(97)76241-6.

Dahl, G. E., and D. Petitclerc. 2003. Management of photoperiod in the dairy herd for improved production and health. J. Anim. Sci. 81(Suppl_3):11-17. https://doi.org/10.2527/2003.81suppl_311x.

Drijfhout, W. J., H. F. Brons, N. Oakley, R. M. Hagan, C. J. Grol, and B. H. C. Westerink. 1997. A microdialysis study on pineal melatonin rhythms in rats after an 8-h phase advance: New characteristics of the underlying pacemaker. Neuroscience 80:233-239. https://doi.org/10.1016/S0306-4522(97)00080-8.

Edmonson, A. J., I. J. Lean, L. D. Weaver, T. Farver, and G. Webster. 1989. A body condition scoring chart for Holstein dairy cows. J. Dairy Sci. 72:68-78. https://doi.org/10.3168/jds.S0022 -0302(89)79081-0.

Elliott, J. A. 1976. Circadian rhythms and photoperiodic time measurement in mammals. Fed. Proc. 35:2339-2346.

Eriksson, L., M. Valtonen, J. T. Laitinen, M. Paananen, and M. Raikkonen. 1998. Diurnal rhythm of melatonin in bovine milk: pharmacokinetics of exogenous melatonin in lactating cows and goats. Acta Vet. Scand. 39:301-310. https://doi.org/10.1186/ BF03547778.

Evans, N. M., and R. R. Hacker. 1989. Effect of chronobiological manipulation of lactation in the dairy cow. J. Dairy Sci. 72:29212927. https://doi.org/10.3168/jds.S0022-0302(89)79443-1.

Fariña, S. R., S. C. Garcia, W. J. Fulkerson, and I. M. Barchia. 2011. Pasture-based dairy farm systems increasing milk production 
through stocking rate or milk yield per cow: Pasture and animal responses. Grass Forage Sci. 66:316-332. https://doi.org/10.1111/ j.1365-2494.2011.00795.x.

Fernandez, D. C., Y.-T. Chang, S. Hattar, and S.-K. Chen. 2016. Architecture of retinal projections to the central circadian pacemaker. Proc. Natl. Acad. Sci. USA 113:6047-6052. https://doi.org/10 $.1073 /$ pnas. 1523629113 .

Fève-Montange, M., E. Van Cauter, S. Refetoff, D. Désir, J. Tourniaire, and G. Copinschi. 1981. Effects of "jet lag" on hormonal patterns. II. Adaptation of melatonin circadian periodicity. J. Clin. Endocrinol. Metab. 52:642-649. https://doi.org/10.1210/jcem-52 $-4-642$.

Gomes, P. R. L., L. C. Motta-Teixeira, C. C. Gallo, D. do Carmo Buonfiglio, L. S. de Camargo, T. Quintela, R. J. Reiter, F. G. do Amaral, and J. Cipolla-Neto. 2021. Maternal pineal melatonin in gestation and lactation physiology, and in fetal development and programming. Gen. Comp. Endocrinol. 300:113633. https://doi .org/10.1016/j.ygcen.2020.113633.

Hanifin, J. P., and G. C. Brainard. 2007. Photoreception for circadian, neuroendocrine, and neurobehavioral regulation. J. Physiol. Anthropol. 26:87-94. https://doi.org/10.2114/jpa2.26.87.

Hansen, P. J. 1985. Seasonal modulation of puberty and the postpartum anestrus in cattle: A review. Livest. Prod. Sci. 12:309-327. https://doi.org/10.1016/0301-6226(85)90131-9.

Hansen, P. J., and E. R. Hauser. 1983. Genotype $\times$ environmental interactions on reproductive traits of bovine females. III. Seasonal variation in postpartum reproduction as influenced by genotype, suckling and dietary regimen. J. Anim. Sci. 56:1362-1369. https:/ /doi.org/10.2527/jas1983.5661362x.

Hansen, P. J., L. A. Kamwanja, and E. R. Hauser. 1983. Photoperiod influences age at puberty of heifers. J. Anim. Sci. 57:985-992. https://doi.org/10.2527/jas1983.574985x.

Jácome, I., L. Rossi, and R. Borille. 2014. Influence of artificial lighting on the performance and egg quality of commercial layers: A review. Braz. J. Poult. Sci. 16:337-344. https://doi.org/10.1590/ 1516-635X1604337-344.

Kassim, N. S. I., A. A. Afify, and H. Z. Hassan. 2008. Effect of photoperiod length on some reproductive traits and hormonal profiles in buffalo heifers. Am. Euras. J. Agric. Environ. Sci. 3:646-655.

Kennaway, D. J. 1994. Effect of a phase advance of the light/dark cycle on pineal function and circadian running activity in individual rats. Brain Res. Bull. 33:639-644. https://doi.org/10.1016/ 0361-9230(94)90227-5.

Kennedy, A. D., R. D. Bergen, T. J. Lawson, J. A. Small, and D. M. Veira. 2004. Effects of evening feeding and extended photoperiod on growth, feed efficiency, live animal carcass traits and plasma prolactin of beef heifers housed outdoors during two Manitoba winters. Can. J. Anim. Sci. 84:491-500. https://doi.org/10.4141/ A03-028.

Lacasse, P., C. M. Vinet, and D. Petitclerc. 2014. Effect of prepartum photoperiod and melatonin feeding on milk production and prolactin concentration in dairy heifers and cows. J. Dairy Sci. 97:3589-3598. https://doi.org/10.3168/jds.2013-7615.

Lawson, T. J., and A. D. Kennedy. 2001. Inhibition of nighttime melatonin secretion in cattle: Threshold light intensity for dairy heifers. Can. J. Anim. Sci. 81:153-156. https://doi.org/10.4141/A00-058.

Lewis, P. D. 2006. A review of lighting for broiler breeders. Br. Poult. Sci. 47:393-404. https://doi.org/10.1080/00071660600829092.

Li, H., J. Wei, F. Ma, Q. Shan, D. Gao, Y. Jin, and P. Sun. 2020. Melatonin modulates lactation by regulating prolactin secretion via tuberoinfundibular dopaminergic neurons in the hypothalamuspituitary system. Curr. Protein Pept. Sci. 21:744-750. https://doi .org/10.2174/1389203721666200511093733.

Marcek, J. M., and L. V. Swanson. 1984. Effect of photoperiod on milk production and prolactin of Holstein dairy cows. J. Dairy Sci. 67:2380-2388. https://doi.org/10.3168/jds.S0022-0302(84)81586 $-6$.

Miller, A. R. E., E. P. Stanisiewski, R. A. Erdman, L. W. Douglass, and G. E. Dahl. 1999. Effects of long daily photoperiod and bovine somatotropin (Trobest) on milk yield in cows. J. Dairy Sci.
82:1716-1722. https://doi.org/10.3168/jds.S0022-0302(99)75401 $-9$.

Moore, R. Y., and V. B. Eichler. 1972. Loss of a circadian adrenal corticosterone rhythm following suprachiasmatic lesions in the rat. Brain Res. 42:201-206. https://doi.org/10.1016/0006 -8993(72)90054-6.

Morgan, P. J., and J. G. Mercer. 1994. Control of seasonality by melatonin. Proc. Nutr. Soc. 53:483-493. https://doi.org/10.1079/ PNS19940059.

Murphy, B. A., C. M. Walsh, E. M. Woodward, R. L. Prendergast, J. P. Ryle, L. H. Fallon, and M. H. T. Troedsson. 2014. Blue light from individual light masks directed at a single eye advances the breeding season in mares. Equine Vet. J. 46:601-605. https://doi .org/10.1111/evj.12153.

Muthuramalingam, P., A. D. Kennedy, and R. J. Berry. 2006. Plasma melatonin and insulin-like growth factor-1 responses to dim light at night in dairy heifers. J. Pineal Res. 40:225-229. https://doi .org/10.1111/j.1600-079X.2005.00303.x.

Nolan, M. B., C. M. Walsh, N. Duff, C. McCrarren, R. L. Prendergast, and B. A. Murphy. 2017. Artificially extended photoperiod administered to pre-partum mares via blue light to a single eye: Observations on gestation length, foal birth weight and foal hair coat at birth. Theriogenology 100:126-133. https://doi.org/10.1016/j .theriogenology.2017.06.012.

Perreau-Lenz, S., A. Kalsbeek, P. Pévet, and R. M. Buijs. 2004. Glutamatergic clock output stimulates melatonin synthesis at night. Eur. J. Neurosci. 19:318-324. https://doi.org/10.1111/j.0953-816X .2003.03132.x

Peters, R. R., L. T. Chapin, K. B. Leining, and H. A. Tucker. 1978. Supplemental lighting stimulates growth and lactation in cattle. Science 199:911-912. https://doi.org/10.1126/science.622576.

Peters, R. R., L. T. Chapin, R. S. Emery, and H. A. Tucker. 1981. Milk yield, feed intake, prolactin, growth hormone, and glucocorticoid response of cows to supplemented light. J. Dairy Sci. 64:16711678. https://doi.org/10.3168/jds.S0022-0302(81)82745-2.

Phillips, C. J. C., and S. A. Schofield. 1989. The effect of supplementary light on the production and behaviour of dairy cows. Anim. Sci. 48:293-303. https://doi.org/10.1017/S0003356100040290.

Provencio, I., I. R. Rodriguez, G. Jiang, W. P. Hayes, E. F. Moreira, and M. D. Rollag. 2000. A novel human opsin in the inner retina. J. Neurosci. 20:600-605. https://doi.org/10.1523/JNEUROSCI.20 $-02-00600.2000$.

Ray, D. E., T. J. Halbach, and D. V. Armstrong. 1992. Season and lactation number effects on milk production and reproduction of dairy cattle in Arizona. J. Dairy Sci. 75:2976-2983. https://doi .org/10.3168/jds.S0022-0302(92)78061-8.

Reddy, A. B., M. D. Field, E. S. Maywood, and M. H. Hastings. 2002. Differential resynchronisation of circadian clock gene expression within the suprachiasmatic nuclei of mice subjected to experimental jet lag. J. Neurosci. 22:7326-7330. https://doi.org/10.1523/ JNEUROSCI.22-17-07326.2002.

Reksen, O., A. Tverdal, K. Landsverk, E. Kommisrud, K. E. Bøe, and E. Ropstad. 1999. Effects of photointensity and photoperiod on milk yield and reproductive performance of norwegian red cattle. J. Dairy Sci. 82:810-816. https://doi.org/10.3168/jds.S0022 -0302(99)75300-2.

Rius, A. G., and G. E. Dahl. 2006. Exposure to long-day photoperiod prepubertally may increase milk yield in first-lactation cows. J. Dairy Sci. 89:2080-2083. https://doi.org/10.3168/jds.S0022 $-0302(06) 72277-9$.

Robinson, J. E., and F. J. Karsch. 1987. Photoperiodic history and a changing melatonin pattern can determine the neuroendocrine response of the ewe to daylength. J. Reprod. Fertil. 80:159-165. https://doi.org/10.1530/jrf.0.0800159.

Roussel, J. D., T. E. Patrick, H. C. Kellgren, and C. P. Breidenstein. 1963. Effect of artificial light, temperature, and humidity on physiological response of dairy bulls. J. Dairy Sci. 46:1125-1131. https: //doi.org/https://dx.doi.org/10.3168/jds.S0022-0302(63)89220-6.

Roussel, J. D., T. E. Patrick, H. C. Kellgren, and A. J. Guidry. 1964. Influence of incandescent light on reproductive and physiological 
responses of bovine bulls. J. Dairy Sci. 47:175-178. https://doi .org/10.3168/jds.S0022-0302(64)88613-6.

Salfer, I. J., C. D. Dechow, and K. J. Harvatine. 2019. Annual rhythms of milk and milk fat and protein production in dairy cattle in the United States. J. Dairy Sci. 102:742-753. https://doi.org/10.3168/ jds.2018-15040.

Stanisiewski, E. P., L. T. Chapin, N. K. Ames, S. A. Zinn, and H. A. Tucker. 1988. Melatonin and prolactin concentrations in blood of cattle exposed to 8,16 or 24 hours of daily light. J. Anim. Sci. 66:727-734. https://doi.org/10.2527/jas1988.663727x.

Stephan, F. K., and I. Zucker. 1972. Circadian rhythms in drinking behavior and locomotor activity of rats are eliminated by hypothalamic lesions. Proc. Natl. Acad. Sci. USA 69:1583-1586. https:// doi.org/10.1073/pnas.69.6.1583.

Thapan, K., J. Arendt, and D. J. Skene. 2001. An action spectrum for melatonin suppression: Evidence for a novel non-rod, non-cone photoreceptor system in humans. J. Physiol. 535:261-267. https:/ /doi.org/10.1111/j.1469-7793.2001.t01-1-00261.x.

Vanbaale, M. J., D. V. Armstrong, M. A. Etchebarne, R. M. Mattingly, and J. B. Fiscalini. 2005. Case study: Supplemental light for lactating dairy cows. Appl. Anim. Sci. 21:521-523. https://doi .org/10.15232/S1080-7446(15)31258-4.

Walsh, C. M., R. L. Prendergast, J. T. Sheridan, and B. A. Murphy. 2013. Blue light from light-emitting diodes directed at a single eye elicits a dose-dependent suppression of melatonin in horses. Vet. J. 196:231-235. https://doi.org/10.1016/j.tvjl.2012.09.003.

West, K. E., M. R. Jablonski, B. Warfield, K. S. Cecil, M. James, M. A. Ayers, J. Maida, C. Bowen, D. H. Sliney, M. D. Rollag, J. P. Hanifin, and G. C. Brainard. 2011. Blue light from light-emitting diodes elicits a dose-dependent suppression of melatonin in humans. J. Appl. Physiol. 110:619-626. https://doi.org/10.1152/ japplphysiol.01413.2009.

Yamazaki, S., R. Numano, M. Abe, A. Hida, R. Takahashi, M. Ueda, G. Block, Y. Sakaki, M. Menaker, and H. Tei. 2000. Resetting central and peripheral circadian oscillators in transgenic rats. Science 288:682-685. https://doi.org/10.1126/science.288.5466.682.

\section{ORCIDS}

Barbara A. Murphy () https://orcid.org/0000-0003-2163-7927 Mary M. Herlihy 나 https://orcid.org/0000-0002-3886-0300 Margaret B. Nolan (ㄴ https://orcid.org/0000-0003-1755-853X John G. Furlong ๑ https://orcid.org/0000-0002-4598-3421

Stephen T. Butler ๑ https://orcid.org/0000-0003-1542-8344 